\title{
HISTÓRIA ESCOLAR E PESQUISAS DIDÁTICAS: A FORMAÇÃO DO PROFESSOR PESQUISADOR NO ENSINO DE HISTÓRIA
}

\author{
LEITE $^{1}$, Luciana \\ Universidade Federal de Goiás (UFG)
}

\section{RESUMO}

Este artigo busca discutir a diversidade social, epistêmica e cultural brasileira e o papel do professor-pesquisador nas práticas do ensino de História nas escolas brasileiras. Para tal, desenvolvo uma discussão baseada nos anos de experiência da autora como professora de História na educação básica e, também, por meio de apontamentos sobre a educação indígena atual. Apresentarei, também, como os saberes indígenas mudaram meu olhar sobre a pesquisa e o ensino de História e minha concepção de professor-pesquisador.

Palavras-chave: Ensino de História. Saberes Indígenas. ProfessorPesquisador.

\section{ABSTRACT}

This article seeks to discuss Brazilian social, epistemic and cultural diversity and the role of the teacher-researcher in the teaching of History in Brazilian schools. To that end, I develop a discussion based on the author's years of experience as a history teacher in basic education, and also through notes on current indigenous education. I will also present how indigenous knowledge has changed my perspective on the research and teaching of History and my conception of teacher-researcher.

Key words: History Teaching. Indigenous Knowledge. TeacherResearcher.

Até a década de 1970 predominou uma noção técnica e mecanicista da educação, vista como local de reprodução do conhecimento científico, sujeitada a uma avaliação (acertos e erros)

1 Universidade Federal de Goiás. Professora formadora da Ação "Saberes Indígenas na Escola". 
que se dava no sentido de verificar a aproximação entre o que se ensinava e o que se produzia no âmbito das ciências. Neste contexto, a formação do (a) professor (a) se limitava ao domínio de técnicas de transposição dos saberes pré-definidos pelos programas, pelos currículos escolares e pelos livros didáticos.

Fica aqui evidente que esta concepção de ensino/aprendizagem constrói uma relação hierárquica entre o saber construído no contexto acadêmico e o saber ensinado, tido como uma transposição simplificada, reducionista e simplista do saber científico. Na sala de aula, segundo Paulo Freire, esta hierarquização se desdobrava na relação professor (a) - detentor do conhecimento- e aluno (a), como receptor passivo dos mesmos.

A pesquisa, como elemento primordial na formação do (a) professor (a) e no seu cotidiano profissional, possibilita-nos romper com este paradigma tradicional, valorizar os saberes construídos no contexto escolar e agir/projetar uma escola que esteja em busca de sua autonomia. Todas essas transformações de paradigmas são essenciais por tornarem o campo da educação um campo de pesquisa e de reflexão sobre a práxis, de produção de conhecimentos, de possibilidades de transformação e de crítica social, no qual o professor, ao se tornar ativo no trabalho, possa transpor os limites das exigências curriculares e se abrir para as demandas práticas socioculturais.

Trazemos aqui, então, algumas questões: O que é um professor pesquisador? Como fazer pesquisa em sala de aula? Existem roteiros de pesquisa em sala de aula? O que almejamos quando pesquisamos no contexto escolar?

Para refletir sobre essas questões, em primeiro lugar, deve ser levada em consideração a diversidade social, epistêmica e cultural de nosso país. Ainda que nossa Legislação Educacional tenda a unificar o que deve ser ensinado e o que deve ser aprendido, cada escola constitui-se como um lugar único, apresentando peculiaridades espaciais e temporais como: público escolar; local; contexto cultural e epistemológico; formas de se relacionar com as unidades educacionais externas, como secretarias de educação etc. Portanto, é muito complicado pensarmos em um modelo de professor pesquisador, bem como em um modelo de pesquisa no ensino de História.

O caminho que escolhi para desenvolver esta discussão é uma recomposição de uma estrada que venho percorrendo há mais de quinze anos no ensino escolar básico de Goiânia, mas que, nos 
últimos anos, tem sido enriquecida com a experiência junto aos professores indígenas no curso de Educação Intercultural da UFG (Universidade Federal de Goiás). Portanto, do meu lugar de fala, quero contar como os saberes indígenas me proporcionaram um novo olhar sobre a pesquisa e o ensino de História e, principalmente, instigou-me a um trabalho constante de reflexão e crítica à própria concepção de História que predominou em toda minha formação educacional.

\section{A formação do professor de História}

Como já mencionei acima, desde a década de 70, existe um intenso debate acerca da formação dos professores como pesquisadores. Mas, o fato é que, durante minha graduação (1999 a 2004), vivenciamos um ambiente acadêmico em que a pesquisa na faculdade de História se restringia principalmente ao curso de bacharelado $^{2}$. Esta situação era agravada ainda pela desvalorização dos estudos direcionados ao campo da educação, acompanhando o processo nacional de inferiorização e desprestígio dos profissionais da educação como um todo.

Para além da graduação, esta situação podia ser vista no próprio quadro de alunos nos cursos da pós-graduação, em que praticamente inexistia alguém que fosse professor do ensino básico. Obviamente que isso se desdobra (va) no fato de que os concursos para professor de instituições de ensino superior no Brasil, em sua grande maioria, não contabilizam a experiência daqueles que se dedicaram ao ensino básico.

$\mathrm{Na}$ escola, como professora de História, a este quadro somaram-se ainda as péssimas condições de trabalho e as exigências institucionais que, desde a coordenação e direção até a secretaria estadual de educação e o MEC, passavam longe do que hoje entendemos como professor pesquisador. $\mathrm{Na}$ verdade, em diversos momentos, eu e meus alunos nos perguntávamos o que estávamos fazendo ali, lendo imensos textos dos livros didáticos para saber como as mais diversas sociedades do mundo organizaram-se nos últimos 12.000 anos.

Em uma região da periferia de Goiânia, isso não fazia muito sentido. Foi quando comecei a realizar um projeto em que os alunos

2 Também era notável que os professores que assumiam o curso de 'Didática da História' sofriam uma espécie de preconceito. 
escolhiam o tema que gostariam de pesquisar. O resultado - era de se esperar - foi que nenhum dos alunos escolheu qualquer tema presente nas narrativas dos manuais de história. Cito aqui alguns dos principais exemplos de que me recordo: história da música (funk, rap, sertanejo, gospel); história do bairro; história do futebol; história do grafite; história das testemunhas de Jeová; história das armas.

Eu começava, então, a trilhar o caminho da pesquisa em sala de aula. Alguns anos depois, quando retornei à Universidade para fazer um curso de especialização, deparei-me com um cenário onde o tema do ensino e o dos usos públicos da História tomavam espaço nos debates, nas pesquisas e nas teorias de História. Devo dizer que isto se deu pela divulgação, principalmente, das obras do pensador alemão Jörn Rüsen, cuja tese central consiste em reafirmar a intrínseca relação entre a pesquisa no campo escolar (ideias históricas de professores, alunos, livros didáticos, currículos escolares etc.) e as produções historiográficas acadêmicas.

De ponta a ponta do Brasil, vemos hoje que circula entre milhares de estudantes e pesquisadores a matriz disciplinar de História proposta por este autor. Ao mesmo tempo, cresce o número de pesquisas no campo do ensino de História que se utilizam das ferramentas conceituais propostas por este pensador, incluindo as classificações de tipos de pensamento histórico que ele propõe. Importantes temas, como a questão da interculturalidade, também vêm sido discutidos nos congressos de História a partir deste referencial. Pouco se tem questionado acerca dos problemas de se importar tipologias formuladas em um contexto cultural, político e econômico tão distinto do nosso.

Em razão deste cenário em que hoje se encontra a formação do professor pesquisador no ensino de História, apresento brevemente a seguir alguns desses conceitos veiculados pela teoria alemã da Didática da História. Em seguida, levantaremos algumas críticas a esta proposta de matriz disciplinar, a partir da teoria modernidade/decolonialidade e da prática de pesquisa realizada pelos professores indígenas.

\section{Didática da História e Educação Histórica}

Jörn Rüsen é um dos autores mais conhecidos no Brasil que se dedicam à ressignificação do conceito de Didática da História, dos usos institucionais da História e da relação entre história e formação identitária. De antemão, cabe deixar claro que existe um interesse 
social e político desse autor em proporcionar vias para formação de uma moeda cultural europeia, assim como o euro é hoje a moeda econômica comum. Sua teoria destaca-se por buscar restabelecer os vínculos entre o saber histórico e a vida cultural e prática do tempo presente, destacando que este saber está para além da racionalidade científica, podendo ser encontrado em todos os processos culturais que lidam com a experiência, a interpretação e a gestão das mudanças do homem no tempo.

Assim, por um lado, a Didática da História deixa de ser confinada ao "ensino em sala de aula" e, por outro, redefine os objetivos da produção historiográfica (SILVA; 2014):

Seja como for, a história, como ciência especializada, está sempre em relação íntima com a educação, a política e a arte. Ela necessita articular-se no âmbito dessa relação, sem que disso resulte uma amputação fatal da auto compreensão dos historiadores profissionais, que consistiria em achar que a mera execução do projeto de pesquisa já bastaria para realizar essa relação. (RÜSEN, 2007, p.16)

É importante observarmos que Jörn Rüsen trata a Didática da História como um campo específico de pesquisa da matriz científica da Ciência da História. O esquema a seguir permite-nos visualizar esta perspectiva:

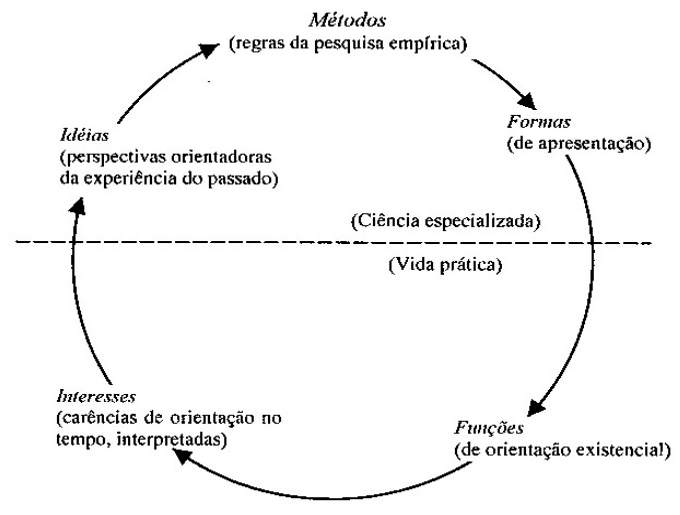

Esquema da matriz disciplinar da ciência da história (Rüsen, 2001, p. 35). 
Um conceito bastante discutido no âmbito da Teoria da História e da Didática da História é o conceito de Consciência Histórica, definido por Rüsen com sendo uma soma de operações mentais que permitem aos homens se organizarem e se orientarem temporalmente, isto é, nos permite interpretar o passado, para compreender o presente e planejar futuros.

Essa interpretação do mundo, através da consciência histórica, se dá em função da necessidade de agirmos de forma intencional para poder viver. É no agir que o homem, com os objetivos que busca na ação, se transpõe para além do que ele e seu mundo são a cada momento. Para agir intencionalmente o homem precisa se orientar no tempo, ou seja, precisa interpretar o que ele experimentou como mudança de si e do mundo ao longo do tempo para que suas intenções possam realizar-se (RÜSEN, 2001).

O resultado desta interpretação é expresso na forma de narrativas, as quais não se limitam à forma científica, ou seja, a historiografia. Sendo assim, Jörn Rüsen questiona a noção de que a consciência histórica deva ser adquirida, por meio do estudo ou das pesquisas científicas, sendo ela fator inato à humanidade, já que todo ser humano sofre as ações do tempo e busca se orientar por meio das interpretações expressas nas narrativas de seu povo (SILVA, 2014).

Como disciplina especializada, a didática da história dedicase à forma com que o pensamento histórico é construído pela consciência histórica, a qual é responsável pela orientação histórica dos indivíduos, tanto na realização prática de suas ações quanto na formação de sua identidade. Fazer com que os alunos adquiram competências que lhes permitam se orientar historicamente pelo desenvolvimento da consciência histórica é a questão central das pesquisas da didática da História. Portanto, o aprendizado histórico, como objetivo de reflexão da didática, consiste em possibilitar o desenvolvimento de competências da consciência histórica que são necessárias para resolver problemas práticos de orientação com o auxílio do saber histórico (RÜSEN, 2010).

A narrativa histórica é a forma linguística dentro da qual a consciência histórica expressa-se e realiza a sua função de orientação. Ela pode ser considerada a competência fundamental da consciência histórica que se pretende alcançar com a aprendizagem histórica. Rüsen classifica a narrativa histórica em quatro tipos:

- tradicional: em que as experiências do tempo são percebidas e interpretadas no interior de tradições as quais se tornam o referencial 
de orientação, ou seja, o indivíduo age e constitui sua identidade de acordo com as normas sociais da tradição à qual pertence;

- exemplar: tem-se a ideia de que a história se repete e, por isso, podemos, a partir do conhecimento do passado, criar regras e maneiras de agir no sentido de evitar cometer os mesmos erros;

- crítica: o modelo de interpretação da vida prática é criticado e anulado, ou seja, nega-se a identidade pessoal e social do modelo cultural afirmado e vigente;

- genética: nesta forma de aprendizado os sujeitos aprendem a considerar sua própria relação como dinâmica e temporal, compreendem a temporalidade de sua identidade não como algo fixo, mas como algo em constante formação e desenvolvimento, e ao mesmo tempo se tornam capazes de estabelecer uma efetiva relação entre passado, presente e futuro para orientação da vida prática no mundo moderno.

Essa classificação tem sido utilizada como um dos principais referenciais teóricos da Educação Histórica. As pesquisas neste campo têm sido desenvolvidas em diversos países da Europa, África, Ásia e América, e centram-se na investigação das ideias históricas prévias dos alunos como fator diretivo na preparação das aulas e na escolha e no desenvolvimento do tema em sala de aula.

A Educação Histórica, como método de investigação no ensino de história, apresenta-nos um leque de possibilidades temáticas bem como epistêmicas:

- o que os estudantes querem estudar;

- como os alunos validam os relatos históricos;

- quais as perspectivas dos jovens acerca da histórica de seu país;

- como os estudantes pensam a utilidade da história em situações de conflitos militares, etnicorraciais, sociais, econômicos e religiosos;

- como os alunos definem conceitos fundamentais da ciência da história (tempo, fonte histórica, narrativa etc.)

- como os jovens interpretam o passado para se orientarem para o futuro;

- como determinados segmentos sociais são representados nos livros didáticos;

- que referenciais teóricos metodológicos predominam nos livros didáticos e nas aulas dos professores;

- como se dá a relação legislação educacional e saber prático escolar etc.

A educação histórica inegavelmente tem possibilitado aos professores de história situarem-se como pesquisadores em sala de 
aula, de forma que hoje, nos encontros e congressos, temos abertas várias mesas de debates e trocas de experiências de pesquisas realizadas no contexto escolar.

No entanto, há uma série de questões relativas ao referencial teórico, aqui apresentado, que pouco são discutidas e que me surgiram a partir da experiência com os professores indígenas. Como cada povo indígena entende o que nós definimos como 'história'? A orientação temporal é mesmo o fator essencial de orientação das ações humanas no mundo? Seria a História um conhecimento que se constrói separadamente dos outros saberes? A matriz disciplinar da História, enquanto ciência, como nos mostra a figura 1, não estabelece uma relação hierárquica entre as diversas formas de narrar a experiência humana e a historiografia produzida a partir do método eurocêntrico?

Neste sentido, apresento a seguir outro referencial teórico que pretende trazer para nossas ações e reflexões outras formas de pensar e ser no/com o mundo.

\section{Modernidade/Decolonialidade/Interculuralidade}

São os povos indígenas e quilombolas os verdadeiros idealizadores e realizadores (pela práxis) do que hoje conhecemos como Movimento Modernidade/Decolonialidade. A luta pela terra avança na luta pela autonomia epistêmica, pela organização de suas escolas, pelo reconhecimento de suas pedagogias próprias, pelas patentes de suas descobertas medicinais, pelo diálogo não hierarquizado entre os povos.

É neste contexto que se desenvolve a proposta do movimento latino-americano "modernidade/decolonialidade" de visualizar o processo de inferiorização das diferentes epistemologias das populações pré-colombianas, tanto no período colonial como no período pós-colonial. É sob outra perspectiva espaço/temporal que os pensadores ligados a este movimento apresentam a formação da modernidade europeia, o que é de grande valia para repensarmos a hegemoneidade das narrativas históricas eurocêntricas.

No que concerne à pesquisa em sala de aula, considero aqui de suma importância a reflexão de Santiago Castro-Gómez sobre a "La Hybris del punto cero", como postura adotada pelo pesquisador que observa, mas não é observado. O surgimento das ciências humanas, entre os séculos XVIII e XIX, foi essencial no processo de 
construção deste imaginário: de um lado a Europa (racional, moderna, pesquisadora) e do outro as periferias (o passado, o primitivo, o préracional, aquele que é estudado).

Castro Gómez assinala que a centralidade da crítica ao eurocentrismo consiste na visualização do colonialismo não só como expropriação econômica e territorial, mas como expropriação epistêmica. A imagem do progresso histórico se "sostenien sobre uma maquinaria geopolítica de saber/poder que há declarado como 'ilegítima' la existência simultânea de distintas voces culturales y formas de producir conocimientos". (GÓMEZ, 2005, p. 26) A escola é, certamente, uma das estratégias utilizadas pela colonialidade do poder.

Vejamos como um professor indígena pensa essa questão:

Tem vez que me pergunto: Por quê? Pra quê serve a escola, sendo que a nossa educação sai da casa, da casa de Aruanã, dos rios, da mata, andando na praia, sem preocupar com as horas, sem depender da regra do homem branco? Para conseguir alguma coisa é difícil, mas juntos nós vamos pensar e produzir novas epistemologias, e daí conseguiremos a produção de material didático bilíngue e intercultural. [Esse é] um interesse nosso e da comunidade e favorável às escolas indígenas. (Iòlò Samuel Javaé/Projeto Extraescolar/np)

Para Iòlò Samuel Javaé e outros professores indígenas, a escola formal até então tem desprezado os espaços e as formas próprias de produção e circulação dos saberes indígenas. Historicamente, a educação indígena esteve diretamente vinculada a interesses estatais e religiosos, permanecendo por séculos subjugada a um modelo político, econômico e cultural que se constituiu sobre as bases de teorias raciais, sustentadas em grande parte pelas próprias ciências humanas. A fala do professor Iòlò Javaé instiga-nos a aprofundar na questão do contexto cultural da escola em que o professor atua como pesquisador e, até mesmo, a questionar os modelos e padrões de pesquisa construídos a partir dos modelos eurocêntricos de pesquisa e deveiculação do conhecimento. É neste sentido que apresentaremos as pesquisas desenvolvidas por professores indígenas no Curso de Educação Intercultural da UFG. 
O curso de Educação Intercultural para Professores Indígenas constitui-se hoje como importante lócus de produção de pesquisa sobre a história, os saberes e a educação (escolar e comunitária) indígena. Baseia-se nos princípios de Sustentabilidade e Diversidade, definidos com base na realidade das sociedades indígenas, no reconhecimento da diferença étnica, na situação em que cada comunidade vive e no seu relacionamento com outros povos.

É destinado a professores indígenas dos estados de Goiás, Mato-Grosso, Maranhão e Tocantins, os quais compõem o etnoterritório da região Araguaia-Tocantins, sendo etnoterritório assim definido pelo Ministério da Educação na Conferência Nacional de Educação Escolar Indígena (2009):

... independentemente da divisão político-
administrativa do país, as terras indígenas, mesmo
que descontínuas, ocupadas por povos indígenas
que mantém relações intersocietárias caracterizadas
por raízes sociais e históricas, relações políticas e
econômicas, filiações linguísticas, valores e práticas
culturais compartilhadas. (BRASIL, 2009).

Os professores participantes do curso elaboram seus projetos extraescolares articulando a escola indígena à comunidade local, pesquisando as experiências históricas e conhecimentos dos sábios da aldeia, estudando técnicas tradicionais de produção de artesanato, alimentação de roça, pintura corporal etc. Ao registrarem e pesquisarem, os professores indígenas na verdade estão em busca da libertação de suas escolas, marcadas desde o início, pela imposição dos padrões do colonizador. A elaboração de livros, jogos e brincadeiras parte do conhecimento da própria comunidade e o articulam ao conhecimento não indígena, resultando disso materiais escritos na língua materna e elaborados pelos especialistas da aldeia, independentemente de serem educadores na escola formal.

Em concomitância com a busca pelo reconhecimento de seus territórios, de suas línguas e de seus saberes, os povos indígenas trouxeram à tona propostas até então nunca discutidas. É o caso dos conceitos de interculturalidade e transdisciplinaridade, também pilares da Proposta Político Pedagógica do Curso de Educação Intercultural, que podem ser mais bem compreendidos pelo projeto elaborado pelo professor/aluno Kurisiri Javaé 
Por meio da escolha do Tema Contextual, 'Plantas Medicinais do Povo Javaé' e com base na interculturalidade e na transdisciplinaridade, meu trabalho de pesquisa foi feito através de seminários com os profissionais da área de saúde da Cidade de Formoso no Tocantins. Também realizei entrevistas com sábios do povo Javaé, portadores do conhecimento acerca das plantas medicinais, como a Sra. Belcina Kunaru Javaé, que vive na Aldeia Javaé São João e da Sra. Adelaide Xiwela Javaé, que vive na mesma aldeia. Além disto, contei com a colaboração da enfermeira do posto de saúde da Aldeia São João, a Sra. Maria dos Reis, sempre tendo em mente o diálogo entre diferentes saberes. (Projeto Extraescolar, s/p)

Vejamos então alguns resultados das pesquisas realizadas pelos professores indígenas:

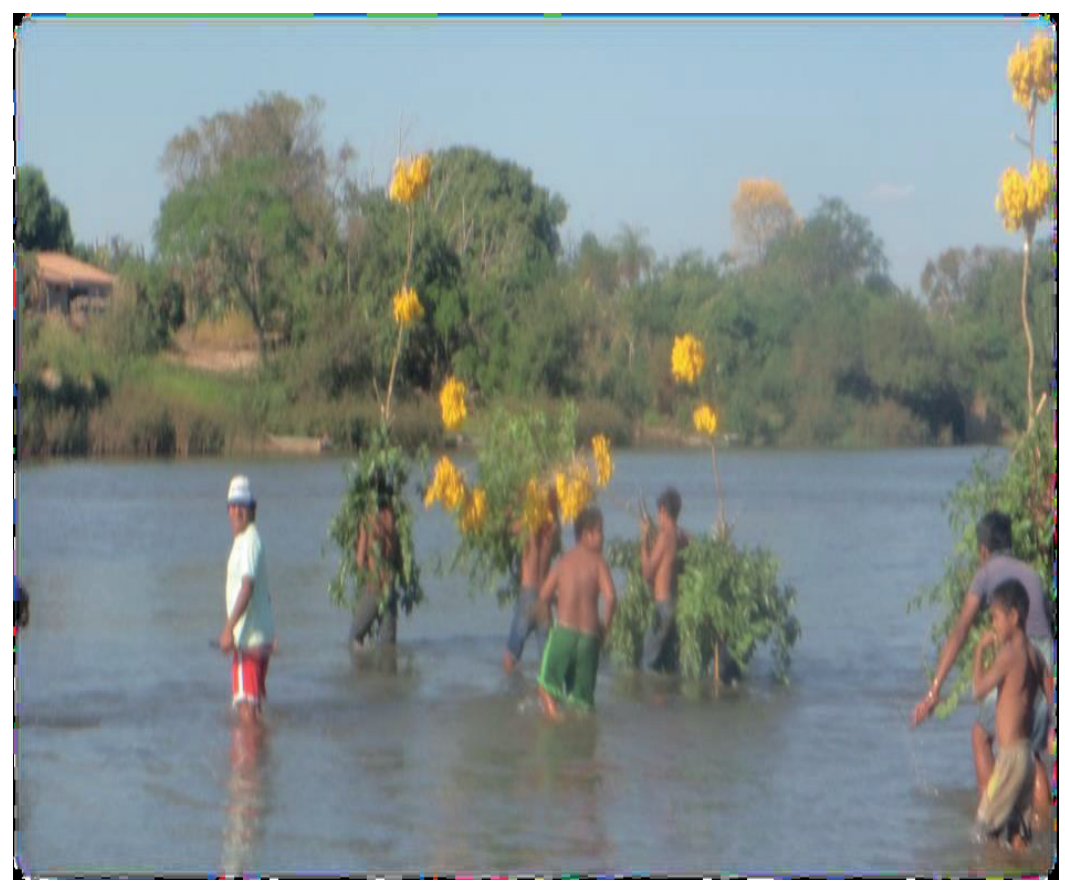

Figura 1: Projeto extraescolar. 'Ihyhy: brincadeira das flores". Professor Romildo Ixariri Javaé. Aldeia Canoanã: 2016. 
Neste projeto, realizado na escola da aldeia Canoanã Javaé (Ilha do Bananal), o professor Romildo pesquisou junto aos mais velhos da comunidade - em especial o professor Ijaú - a brincadeira Ihyhy, que há muitos anos não acontecia mais. É uma brincadeira em que os meninos fazem uma espécie de roupa com as flores do ipê, atravessam o rio e vão para o pátio, onde as meninas correm atrás deles para tentar pegar o buquê. Foi um trabalho lindo e, ao vermos o vídeo, sentimos que havia um clima de imensa alegria entre as crianças quando praticaram essa brincadeira que para elas é nova, mas que para os mais velhos é como se acordassem o passado.

Como afirmou o professor Romildo, essa não foi apenas uma pesquisa para servir de registro histórico para o futuro, mas tornouse uma prática na escola que permite às crianças brincarem, aprender sobre os ciclos das flores do ipê, construírem artesanalmente seus brinquedos, correr, se divertir e reviver saberes adormecidos.

Outro exemplo importante são os projetos político pedagógicos (PPP) elaborados pelos alunos do curso de especialização. Para desenvolvê-los os alunos primeiramente pesquisam e registram as formas de organização de suas comunidades, bem como as propostas de escola almejadas. Assim, o PPP passa ser algo construído como uma ação pela autonomia da escola indígena e pela valorização de seus saberes perante as políticas educacionais que persistem na uniformização do conhecimento, violentamente imposta.

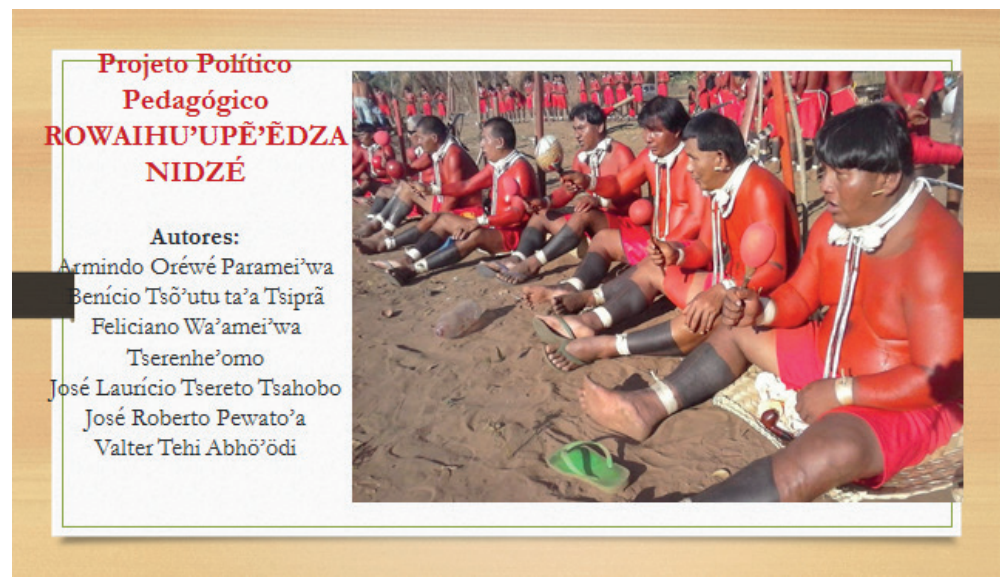

Trata-se, portanto, de inserir a pesquisa não só no cotidiano escolar. Em um contexto mais amplo, a pesquisa deve se tornar instrumento de luta ativa contra as matrizes impostas pelas políticas educacionais, os currículos nacionais, as avaliações, os concursos, os 
interesses econômicos de grupos empresariais que atuam no campo da educação etc. A partir da aproximação destas duas perspectivas de pesquisa no ensino de história retornemos a nossas questões iniciais: "O que é ser professor pesquisador? Como fazer pesquisa em sala de aula? Existem roteiros de pesquisa em sala de aula? O que almejamos quando pesquisamos no contexto escolar?". Ser professor pesquisador é, portanto, se posicionar perante diversas possibilidades de pensarmos o que é ciência da História, o que é ensino e o que é aprendizagem histórica, o que é dialogar com a comunidade escolar e, principalmente, refletir como se colocar mediante a ideia pesquisador/objeto de pesquisa. Finalizo este texto indagando a vocês: "que professor você quer ser?" e "que pesquisador você quer ser?".

Refletindo sobre minha trajetória, as questões que me coloco hoje estão mesmo além de como fazer pesquisa em sala de aula. Questiono minha formação, que colocou a História como interpretação do ser e estar da humanidade no tempo. Questiono se o ser pesquisador é aquele que observa e analisa, ou aquele que aprende. Com o conhecimento dos diversos povos indígenas com quem tenho convivido, aprendi que não estamos apenas no tempo, estamos em um lugar, somos parte da natureza e nos orientamos a partir dela. Os humanos, os seres mágicos, os pássaros e os animais, todos têm história. Digo que, com isso, retornei à sala de aula com o objetivo de compartilhar com meus alunos a riqueza daquilo que a ciência ocidental ensinou-nos a chamar de 'mitos' ou 'estórias'. Hoje nos perguntamos quantas maneiras devem existir no mundo de aprender e de compartilhar o que aprendemos. Como nossas avós que nunca foram à escola, como os trabalhadores do campo, como os grafiteiros, como os funkeiros, como os rapers etc.

\section{REFERENCIAS}

ASHBY, Rosalyn. Métodos dos alunos para validar relatos históricos. In: Estudos de Consciência Histórica na Europa, América, Ásia e África. Actas das Sétimas Jornadas Internacionais de Educação Histórica. Minhografe-Artes Gráficas, Lda. Braga-2008. p. 33-46

BARCA, Izabel. Estudos de Consciência Histórica em Portugal: de Jovens Portugueses acerca da História. In: Estudos de Consciência Histórica na Europa, América, Ásia e África. Actas das Sétimas Jornadas Internacionais de Educação Histórica. Minhografe-Artes Gráficas, Lda. Braga-2008. p. 47-54. 
CASTRO-GÓMEZ, Santiago. La hybris del punto cero: ciencia, raza e ilustración en la Nueva Granada (1750-1816). Santiago Castro-Gómez. - 1a ed. - Bogotá: Editorial Pontifícia Universidad Javeriana, 2005.

FONSECA, Selva Guimarães. Caminhos da História ensinada. Campinas: Papirus-1993.

FREIRE, Paulo. Pedagogia do oprimido. $17^{\mathrm{a}}$ edição. Rio de Janeiro: Paz e Terra. 1987.

GÓMEZ, Santiago. La pos colonialidad explicada a los ninõs. Colombia. Editora: Universidade del Cauca, 2005.

LIBÂNEO, José Carlos. Didática na formação de professores: entre a exigência democrática de formação cultural e científica e as demandas das práticas socioculturais. In: Didática e formação de professores: complexidade e transdisciplinaridade. Porto Alegre: Sulina, 2013. p. 51- 82.

RÜSEN, Jörn. Introdução: significados do pensamento de Jörn Rüsen para investigações na área de educação histórica. In: Jörn Rüsen e o ensino de história. Curitiba: Ed. UFPR, 2010. p.11-22.

RÜSEN, Jörn. Aprendizagem histórica: esboço de uma teoria. In: Aprendizagem Histórica: fundamentos e paradigmas. Curitiba: W. A. Editores, 2012. p. 69-112.

RÜSEN, Jörn. Didática - Funções do saber histórico. In: História Viva: teoria da história, formas e funções do conhecimento histórico. Brasília: Editora de Brasília, 2007. p. 85-121.

WALSH, C. Interculturalidade, crítica e pedagogia decolonial: in-surgir, re-existir e reviver. In: CANDAU, V. M. (Org.). Educação intercultural na América Latina: entre concepções, tensões e propostas. Rio de Janeiro: 7 Letras, 2009. P. 12-43.

WALSH, Catherine. Pedagogias decoloniais: Prácticas insurgentes de resistir, (re)existir y (re) vivir. Série: Pensamiento decolonial. Tomo I. 